Full length article

\title{
Functional protein-based nanomaterial produced in microorganisms recognized as safe: A new platform for biotechnology
}

\author{
Olivia Cano-Garrido ${ }^{\mathrm{a}, \mathrm{b}, \mathrm{c}}$, Alejandro Sánchez-Chardi ${ }^{\mathrm{d}}$, Sílvia Parés ${ }^{\mathrm{e}}$, Irene Giró ${ }^{\mathrm{f}}$, Witold I. Tatkiewicz ${ }^{\mathrm{c}, \mathrm{f}}$, \\ Neus Ferrer-Miralles ${ }^{\mathrm{a}, \mathrm{b}, \mathrm{c}}$, Imma Ratera ${ }^{\mathrm{c}, \mathrm{f}}$, Antonino Natalello ${ }^{\mathrm{g}}$, Rafael Cubarsi ${ }^{\mathrm{h}}$, Jaume Veciana ${ }^{\mathrm{c}, \mathrm{f}}$, \\ Àlex Bach ${ }^{\mathrm{e}, \mathrm{i}}$, Antonio Villaverde ${ }^{\mathrm{a}, \mathrm{b}, \mathrm{c}}$, Anna Arís ${ }^{\mathrm{e}, *}$, Elena Garcia-Fruitós ${ }^{\mathrm{a}, \mathrm{b}, \mathrm{c}, *}$ \\ a Institut de Biotecnologia i de Biomedicina, Universitat Autònoma de Barcelona, 08193 Cerdanyola del Vallès, Spain \\ ${ }^{\mathrm{b}}$ Departament de Genètica i de Microbiologia, Universitat Autònoma de Barcelona, 08193 Cerdanyola del Vallès, Spain \\ ${ }^{\mathrm{C}}$ CIBER de Bioingeniería, Biomateriales y Nanomedicina (CIBER-BBN), 08193 Cerdanyola del Vallès, Spain \\ ${ }^{\mathrm{d}}$ Servei de Microscòpia, Universitat Autònoma de Barcelona, Bellaterra, 08193 Barcelona, Spain \\ ${ }^{\mathrm{e}}$ Department of Ruminant Production, Institut de Recerca i Tecnologia Agroalimentàries (IRTA), 08140 Caldes de Montbui, Spain \\ ${ }_{\mathrm{f}}^{\mathrm{f}}$ Department of Molecular Nanoscience and Organic Materials, Institut de Ciència de Materials de Barcelona (ICMAB-CSIC), Bellaterra, 08193 Barcelona, Spain \\ ${ }^{\mathrm{g}}$ Department of Biotechnology and Biosciences, University of Milano-Bicocca, 20126 Milan, Italy \\ ${ }^{\mathrm{h}}$ Departament de Matemàtica Aplicada IV, Universitat Politècnica de Catalunya, Jordi Girona 1-3, 08034 Barcelona, Spain \\ ${ }^{\mathrm{i}}$ Institució Catalana de Recerca $\mathrm{i}$ Estudis Avançats (ICREA), Barcelona, Spain
}

\section{A R T I C L E I N F O}

\section{Article history:}

Received 26 April 2016

Received in revised form 12 July 2016

Accepted 20 July 2016

Available online 21 July 2016

\section{Keywords:}

Endotoxin-free

Functional nanomaterials

GRAS

Lactic acid bacteria

Nanoparticles

\begin{abstract}
A B S T R A C T
Inclusion bodies (IBs) are protein-based nanoparticles formed in Escherichia coli through stereospecific aggregation processes during the overexpression of recombinant proteins. In the last years, it has been shown that IBs can be used as nanostructured biomaterials to stimulate mammalian cell attachment, proliferation, and differentiation. In addition, these nanoparticles have also been explored as natural delivery systems for protein replacement therapies. Although the production of these protein-based nanomaterials in E. coli is economically viable, important safety concerns related to the presence of endotoxins in the products derived from this microorganism need to be addressed. Lactic acid bacteria (LAB) are a group of food-grade microorganisms that have been classified as safe by biologically regulatory agencies. In this context, we have demonstrated herein, for the first time, the production of fully functional, IB-like protein nanoparticles in LAB. These nanoparticles have been fully characterized using a wide range of techniques, including field emission scanning electron microscopy (FESEM), transmission electron microscopy (TEM), dynamic light scattering (DLS), Fourier transform infrared (FTIR) spectroscopy, zymography, cytometry, confocal microscopy, and wettability and cell coverage measurements. Our results allow us to conclude that these materials share the main physico-chemical characteristics with IBs from $E$. coli and moreover are devoid of any harmful endotoxin contaminant. These findings reveal a new platform for the production of protein-based safe products with high pharmaceutical interest.
\end{abstract}

\section{Statement of Significance}

The development of both natural and synthetic biomaterials for biomedical applications is a field in constant development. In this context, $E$. coli is a bacteria that has been widely studied for its ability to naturally produce functional biomaterials with broad biomedical uses. Despite being effective, products derived from this species contain membrane residues able to trigger a non-desired immunogenic responses. Accordingly, exploring alternative bacteria able to synthesize such biomaterials in a safe molecular environment is becoming a challenge. Thus, the present study describes a new type of functional protein-based nanomaterial free of toxic contaminants with a wide range of applications in both human and veterinary medicine.

(ㄷ) 2016 Acta Materialia Inc. Published by Elsevier Ltd. All rights reserved.

\footnotetext{
* Corresponding authors at: Department of Ruminant Production, Institut de Recerca i Tecnologia Agroalimentàries (IRTA), 08140 Caldes de Montbui, Spain (E. Garcia-Fruitós).

E-mail addresses: olivia.cano.garrido@gmail.com (O. Cano-Garrido), Alejandro.Sanchez.Chardi@uab.cat (A. Sánchez-Chardi), silvia.pares@irta.cat (S. Parés), irene.

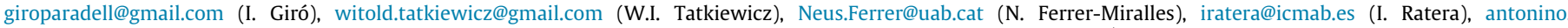

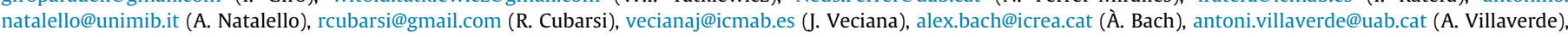
anna.aris@irta.cat (A. Arís), elena.garcia@irta.cat (E. Garcia-Fruitós).
} 


\section{Introduction}

Over the last years, Escherichia coli has been described as a cell factory for the production of self-assembling nanostructured and functional protein materials known as inclusion bodies (IBs) [1-4], which have been studied as stimulators of cell proliferation and differentiation $[5,6]$ and as natural protein delivery systems $[2,7]$. However, in terms of therapeutic applicability of this biomaterial, the presence of lipopolysaccharide (LPS) in the E. coli outer cell membrane becomes a major obstacle. Since LPS, also known as endotoxin, can elicit undesirable immunogenic responses $[8,9]$, FDA regulations establish an endotoxin level limit of $5 \mathrm{EU} / \mathrm{kg} / \mathrm{h}$ for pharmaceutical compounds and medical devices. Thus, all products from $E$. coli, as well as those from other Gram-negative microorganisms, need to be finely purified through costly processes to ensure the removal of any pyrogenic or inflammatory contaminant inherently present in the sample $[8,10]$. Nowadays, the development of a universal and effective method for endotoxin removal remains for the time being unresolved [10], being particularly critical for complex structures such as protein-based nanostructured materials $[9,11]$. This makes it necessary to seek for alternative cell factories, which offer the potential to produce protein biomaterials free from pyrogenic impurities. In this context, Gram-positive (LPS-free) lactic acid bacteria (LAB) are gaining momentum as promising microbial cell factories for both recombinant protein production purposes and as delivery live vectors [12-16]. Indeed, they have been classified by regulatory agencies as generally recognized as safe (GRAS) organisms [17]. Consequently, the development of this biologically-safe production platform based on LAB opens a new era in terms of therapeutic applicability, leaving behind all the important drawbacks associated to $E$. coli-derived recombinant products. However, thus far, the possibility to produce protein-based nanostructures in these bacterial cell factories has not been explored. Contrary to what occurs in $E$. coli, it is widely believed that recombinant proteins produced in LAB are fully soluble, rendering the production of protein-based biomaterials from these GRAS microorganisms rather impossible. Nevertheless, some recent studies, such as that published by Lu and collaborators contradict this general assumption [18]. They described that under the overexpression of a fluorescent protein, highly fluorescent protein clusters are formed in Lactococcus lactis cytoplasm [18]. In this line, our group confirmed the presence of protein deposits in L. lactis cytoplasm using a modified green fluorescent protein [19]. The consideration of all these results together, lead us to believe that L. lactis might potentially be used for the generation of fully safe proteinbased particles that could be further explored as functional nanomaterials. Because almost nothing is known about these nanostructures, the aim of this study was the isolation and detailed characterization of the main morphometric and physico-chemical properties of such a new class of protein deposits. For that, we selected L. lactis, the most used LAB in the field of recombinant protein production as cell factory $[20,21]$. Three relevant proteins in human and veterinary medicine such as bovine metalloproteinase 9 (MMP-9) and 2 (MMP-2) and interferon gamma (IFN- $\gamma$ ) were used herein as model proteins. The obtained data, which revealed the possibility to produce both fully functional and safe protein-based nanoparticles in LAB, offers an attractive opportunity for the production of a new generation of biomaterials with a wide range of biotechnology applications for both human and animal medicine.

\section{Materials and methods}

\subsection{Bacterial strains and plasmids}

L. lactis subsp. cremoris NZ9000 [20] and NZ9000 clpP ${ }^{-}$htrA $\left(\right.$ clpP-htrA; $\mathrm{Em}^{\mathrm{R}}$ ) [22,23] (kindly provided by INRA, Jouy-en-Josas,
France; patent $\mathrm{n}^{\circ}$ EP1141337B1) strains and E. coli MC4100 strain $\left(\right.$ Strep $^{\mathrm{R}}$ ) [24] were used. Three proteins from bovine (Bos taurus) origin were cloned in the $\mathrm{Cm}^{\mathrm{R}}$ pNZ8148 plasmid (MoBiTech): the mature form of the interferon gamma (IFN- $\gamma$ ) (from Gln23 to Thr101 NM_173925) and the catalytic domain of metalloproteinase 9 (MMP-9) (from Phe107 to Pro449 NM_174744) and 2 (MMP-2) (from Tyr110 to Asp45 NM_174745). In addition, a fusion of MMP-9 with an aggregation-prone peptide (ELK16: (LELELKLK) 2 ) was also constructed (MMP-9ELK16). All genes were C-terminally fused to a His-tag for detection and quantification purposes in western blot analysis. Gene sequences were codon optimized (Geneart). In the sequence design we added a $N c o I$ restriction site at $5^{\prime}$ followed by nucleotides CA to restore the reading frame and a $\mathrm{XbaI}$ restriction site at $3^{\prime}$. The digestion product was ligated into the expression plasmid pNZ8148 and ligation product were transformed by electroporation into L. lactis NZ9000 and clpP-htrA competent cells [25]. Electroporation was performed using Gene Pulser from Bio-rad fitted with $2500 \mathrm{~V}, 200 \Omega$ and $25 \mu \mathrm{F}$ in a pre-cooled $2 \mathrm{~cm}$ electroporation cuvette. Following, samples were supplemented with $900 \mu \mathrm{L}$ M17 broth with $0.5 \%$ glucose and incubated for $2 \mathrm{~h}$ at $30^{\circ} \mathrm{C}$. The electroporation mix was centrifuged for $10 \mathrm{~min}$ at $10,000 \times g$ at $4{ }^{\circ} \mathrm{C}$ and the pellet was resuspended in $100-200 \mu \mathrm{L}$ of M17 media and plated. Besides, recombinant Green Fluorescent Protein (rGFP) previously described in $[19,26]$ were also used.

\subsection{Nanoparticle production and purification}

L. lactis strains containing the previously described plasmids were grown in M17 medium enriched with $0.5 \%$ glucose at $30^{\circ} \mathrm{C}$ without shaking. E. coli was grown in LB rich medium at $37^{\circ} \mathrm{C}$, $250 \mathrm{rpm}$. Nanoparticle production was induced by adding $12.5 \mathrm{ng} / \mathrm{mL}$ nisin (Sigma-Aldrich) in L. lactis or $1 \mathrm{mM}$ IPTG in $E$. coli cultures at $\mathrm{OD}_{550 \mathrm{~nm}}=0.5$. After induction, cultures were grown for $3 \mathrm{~h}$. Antibiotics were used for plasmid maintenance at the following concentrations: chloramphenicol $(5 \mu \mathrm{g} / \mathrm{mL})$ and erythromycin $(2.5 \mu \mathrm{g} / \mathrm{mL})$ for L. lactis and ampicillin $(100 \mu \mathrm{g} / \mathrm{mL})$ and streptomycin $(30 \mu \mathrm{g} / \mathrm{mL})$ for $E$. coli.

Once produced, protein nanoparticles were purified using the purification protocol described by [27], including, at the beginning of the process, a mechanical disruption step by French Press. The protocol was performed under sterile conditions and all incubations were carried out under agitation.

The amount of recombinant proteins present in nanoparticles were quantified by denaturing SDS-PAGE as described in [19]. Bands were identified using a commercial polyclonal serum against histidine tag (\#A00186-100 Genscript) and an antimouse secondary antibody (\#170-6516, Bio-Rad). Recombinant protein yield were estimated with a standard curve with known amounts of a GFP-H6 protein. Quantification was performed with the Quantity One software.

\subsection{Field emission scanning electron microscopy (FESEM)}

For nanoparticles morphometry (size and shape), microdrops of protein aggregate suspensions were deposited during $2 \mathrm{~min}$ on silicon wafers (Ted Pella Inc.), air-dried and observed in a FESEM Zeiss Merlin (Zeiss) operating at $2 \mathrm{kV}$. Micrographs of nanoparticles morphology at a nearly native state were acquired with a high resolution in-lens secondary electron (SE) detector. A quantitative analysis of particle size was performed with a total number of 474 nanoparticles using Image J software.

\subsection{Transmission electron microscopy (TEM)}

For ultrastructure, samples were fixed with aldehydes, postfixed with osmium, dehydrated in acetone, embedded in Epon 
resin, and polymerized following conventional methods [28-30]. Ultrathin sections were placed on copper grids, contrasted, and observed with a TEM Jeol JEM-1400 (Jeol Ltd.) equipped with a CCD Gatan ES1000 W Erlangshen camera. For MMP-2, MMP-9 and IFN- $\gamma$ immunolocalization, pellets of bacterial cells and protein nanoparticles were fixed in $4 \%(\mathrm{w} / \mathrm{v})$ paraformaldehyde and $0.1 \%$ (v/v) glutaraldehyde in PB, cryoprotected in sucrose, cryofixed in propane, dehydrated in methanol, embedded in Lowicryl HM20 resin (Polysciences Inc.), and polymerized with UV rays. Ultrathin sections placed on carbon-coated gold grids were labeled for the 3 antigens of interest using rabbit polyclonal primary antibodies (anti-MMP-2: \#AV20016, Sigma-Aldrich; anti-MMP-9: \#50560RP01, Sino Biological Inc.; and anti-IFN- $\gamma$ : \#ab9657, Abcam, at working dilution 1:5, 1:5 and 1:2 respectively) and protein A coupled to $10 \mathrm{~nm}$-gold particles (BBI Solutions), following standard methods [30,31]. Grids were contrasted and examined with a TEM Jeol JEM-1400 at same conditions than previously described.

\subsection{Z-Potential}

Z-Potential characterization of each kind of protein nanoparticles was carried out using dynamic light scattering (DLS) equipment (Malvern Nanosizer). To prevent the electrodes from burning, the samples were prepared in deionized (MilliQ) water, a low ionic strength medium. Each sample was analyzed by triplicate.

\subsection{Proteinase K assay}

Protein nanoparticles were resuspended in PBS and sonicated to obtain a homogenous sample. Kinetic analysis were performed as described in [32]. In control suspensions, MilliQ water was added instead of Proteinase K. Sample was recovered after every measurement to maintain constant the reaction volume. The experiment was done by triplicate.

\subsection{Mathematical modeling}

The dynamics of nanoparticle disaggregation process is described through a mixture of decreasing exponential functions with up to 3 populations according to one of the following 2 models. If the protein of nanoparticles at time $t$ is denoted by $y_{m}(t)$, a mixture without a constant population is given by

$y_{m}(t)=N_{0} e^{-c_{1} t}+\ldots+N_{k} e^{-c_{k} t} ; m=2 \mathrm{k} ; k \geqslant 1$

denoted with an even subscript according to the even number of terms. Otherwise, if there exist a non-disaggregated population, the nanoparticle amount is given by

$y_{m}(t)=N_{0}+N_{1} e^{-c_{1} t}+\ldots+N_{k} e^{-c_{k} t} ; m=2 \mathrm{k}+1 ; k \geqslant 1$

with an odd subscript. In both cases the fit will depend on a set of $m$ parameters $P$ that is evaluated from a least squares fit. Only positive values of $N_{i}$ and $c_{i}$ are allowed. The parameter $N_{i}$ is the initial protein of the $i$-th component and $c_{i}$, in the exponent, provides the expected life $T_{i}=1 / c_{i}$ (the half-life is $t_{i}=\ln 2 / c_{i}$ ). The number of components in the mixture model is $C=\left[\frac{m+1}{2}\right]$ (integer part). From a data array $L=\left\{\left(x_{i}, t_{i}\right) ; i=1, \ldots, n\right\}$, where $x_{i}$ is the nanoparticle amount at time $t_{i}$, we minimize the $\chi^{2}$ of the fit [32]. Among all the possible fits, as increasing $m$ we chose the one satisfying $\ldots>\chi_{m-1}^{2}>\chi_{m}^{2} \leqslant \chi_{m+1}^{2}$.

In the context of the disaggregation process, not all fits are admissible. Indeed, the procedure can be applied in 2 ways: (a) as for each strain, the experiment is repeated $q$ times, there is a number of $q$ arrays by strain that we averaged to build a single array $\bar{L}=E(L)$ ( $E$ means the expected value). We then determined the specific parameters $P^{\prime}$ of the strain. (b) Alternatively, for each strain, each experiment may be fitted separately. This provides $q$ families of parameter sets $P$ that we averaged as $\bar{P}=E(P)$ in order to characterize the strain components. A meaningful fit must fulfill that the values $\bar{P}$ and $P^{\prime}$ match within a low error margin. This is a sufficient condition to accept the fitting, otherwise the strain average values $E(L)$ would not represent the individual experiments. In particular, this implies that the number of components of the strain obtained from the average $E(L)$ and that obtained for each individual experiment must match. The necessary condition for comparing both procedures is to determine the same number of strain components $C$ from the average array and the single arrays. If both approaches provide a different number of strain components, other fittings to reconcile both procedures must be chosen among those with low $\chi^{2}$, preferably among the simplest models, although they do not provide the lowest value.

\subsection{Metalloproteinases activity assay (zymography)}

MMP enzymatic activities were determined by gel 10\% SDSPAGE + $1 \%$ gelatin under non-denaturing conditions. IBs were loaded onto the gel diluted $1: 1$ with a sample loading buffer ( $0.125 \mathrm{M}$ Tris, $0.005 \%$ bromophenol blue, $20 \%$ glycerol, $4 \%$ SDS). Then, the gel was incubated with developing buffer $(50 \mathrm{mM}$ Tris, $0.2 \mathrm{M} \mathrm{NaCl}, 5 \mathrm{mM} \mathrm{CaCl}_{2}, 0.02 \%$ Brij 35) for $48 \mathrm{~h}$ at $37^{\circ} \mathrm{C}$. Lastly, it was dyed with Coomassie and discolored until degradation bands become visible. Densitometry analyses of the bands were performed with the Image J software. Soluble MMP-9 produced in $L$. lactis has been used as a positive control.

\subsection{Fourier transform infrared (FTIR) spectroscopy}

The protein hydrated films were measured by the infrared microscope Varian 610-IR, coupled to the Varian 670-IR spectrometer (both from Varian Australia Pty Ltd.), as reported in [33,34]. In particular, drops of $1-5 \mu \mathrm{L}$ of the soluble protein and nanoparticles were deposited on $\mathrm{a} \mathrm{BaF}_{2}$ window. The FTIR spectra were then collected in transmission mode after the solvent evaporation in order to obtain a uniform protein film on the window. Under these conditions [33,34] spectra with high signal-to-noise ratio without detectable scattering effects were obtained [35] (Suppl Fig. 1).

For hydrogen/deuterium (H/D) exchange experiments, the protein film on the $\mathrm{BaF}_{2}$ window was hydrate by adding $5 \mu \mathrm{L}$ of a solution of $1 / 4$ of glycerol $/ \mathrm{D}_{2} \mathrm{O}$ ratio $(\mathrm{w} / \mathrm{w})$ around the dried film. The sample was then tightly closed by a second window using a flat O-ring.

\subsection{Proliferation assay}

Human skin fibroblast cells (1BR3.G) were grown at $37^{\circ} \mathrm{C}$ and $10 \% \mathrm{CO}_{2}$ on protein nanoparticles-decorated surfaces [36]. A total of $1 \mu \mathrm{g}$ of rGFP protein-based nanoparticles from L. lactis and E. coli were added to each well of an untreated Costar 3370 plate and incubated with $100 \mu \mathrm{L}$ of Dulbecco's Modified Costar Medium (DMEM) without serum at $4{ }^{\circ} \mathrm{C}$ overnight. After incubation, 1BR3. G cells were added (5000 cells per well) in $100 \mu \mathrm{L}$ DMEM medium with $2 \%$ fetal bovine serum (FBS). As controls, we plated cells on non-decorated wells and we also used wells decorated with nanoparticles but without cells. Plates were incubated at $37^{\circ} \mathrm{C}$ for 24,48 and $72 \mathrm{~h}$, and the MTT proliferation cell assay was performed as described elsewhere [37]. 


\subsection{Nanoparticles internalization (cytometry)}

HeLa cells (60,000 cells per well) were seeded in treated 12-well plates in the presence of Minimum Essential Medium (MEM- $\alpha$ ) medium supplemented with $10 \%$ FBS and 2 mM Glutamax (Gibco) [30]. After incubation at $37{ }^{\circ} \mathrm{C}$ and $5 \% \mathrm{CO}_{2}$ for $24 \mathrm{~h}$, the medium was removed and the cells were washed with Dulbecco's Phosphate-Buffered Saline (DPBS). Then, $5 \mu \mathrm{g}$ of rGFP based protein nanoparticles from $L$. lactis and $E$. coli were suspended in MEM- $\alpha$ containing 10\% FBS and $2 \mathrm{mM}$ Glutamax and added per well. After $48 \mathrm{~h}$, cell samples were treated for $15 \mathrm{~min}$ in $1 \mathrm{mg} / \mathrm{mL}$ trypsin and samples were analyzed on a FACSCanto system (Becton Dickinson) using a $15 \mathrm{~W}$ air-cooled argon-ion laser at $488 \mathrm{~nm}$ excitation for GFP. Fluorescence emission was measured with a $530 / 30 \mathrm{~nm}$ band pass filter.

\subsection{Nanoparticles internalization (confocal microscopy)}

HeLa cells $(100,000$ cells/mL) were seeded on MatTek culture dishes with MEM- $\alpha$ medium supplemented with 10\% FBS and $2 \mathrm{mM}$ Glutamax (Gibco), and incubated at $37^{\circ} \mathrm{C}$ and $5 \% \mathrm{CO}_{2} .5 \mu \mathrm{g}$ rGFP nanoparticles were added to cells in the presence of Optipro medium (Gibco) and incubated $\mathrm{O} / \mathrm{N}$. For confocal analysis, cell membrane and nuclei were stained and stacks were obtained as described elsewhere [38].

\subsection{Modification of gold substrates with mixed self-assembled monolayers (SAMs)}

SAMs with different proportions of 1-undecenethiol $\left(-\mathrm{CH}_{3}\right.$ terminated) and 11-mercapto-1-undecanol ( $-\mathrm{OH}$ terminated) were prepared by immersion of gold substrates in an ethanolic solution of the thiols with the appropriate molar ratio for $24 \mathrm{~h}$ as described elsewhere [5].Then, the substrates were dried under a stream of $\mathrm{N}_{2}$ getting surfaces with different wettability properties.

\subsection{Deposition of protein nanoparticles on SAM modified substrates and surface covering analysis}

Substrates with mixed SAMs were immersed in the protein nanoparticles suspensions for $2 \mathrm{~h}$, and rinsed with MilliQ water. Light microscopy images were obtained using an Olympus Bx51 microscope and surface coverage analysis using ImageJ 1.47.

\subsection{Wettability}

The wettability of mixed thiols SAMs on gold surfaces before and after protein nanoparticles deposition was determined via static contact angle (CA) measurements using a DSA100 from KRÜSS.

\subsection{Statistical analysis}

Data were analyzed using a general linear model (JMP, SAS Institute Inc.). For the analysis, strain, protein, and the interaction between strain and protein were used as fixed effects. When more than 2 means were compared, differences were established using the Tukey's multiple mean separation test. Data were previously transformed when necessary to achieve a normal distribution. Results are expressed as the means of non-transformed data \pm standard error of mean (SEM), except otherwise stated.

\section{Results}

\subsection{Ultrastructural analysis of L. lactis nanoparticles by electron microscopy}

TEM micrographs obtained of $L$. lactis cells under overproduction conditions showed the formation of regular intracytoplasmic protein deposits in practically all cells (Fig. 1A). Furthermore, the specific immunolocalization confirmed that these deposits are formed by the recombinant protein (Fig. 1A, right images). In a second step, once the production of these protein deposits in L. lactis was successfully assessed, MMP-9, MMP-2 and IFN- $\gamma$ nanoparticles were isolated and quantified by Western blot (data not shown). The ultrastructural morphology of the nanomaterial was analyzed by FESEM and TEM (Fig. 1B and C) and the obtained micrographs allowed us to conclude that these protein deposits corresponded to well structured and compact-defined particles within the nanoscale range (Fig. $1 \mathrm{~B}$ and $\mathrm{C}$ ).

\subsection{Size determination of $L$. lactis nanoparticles}

By the analysis of FESEM micrographs, we determined the size of the nanostructures, obtaining values ranging between 300 and $450 \mathrm{~nm}$ (Table 1). Extreme mean values were found for the NZ9000 clpP $^{-} h$ trA $^{-}$strain (hereafter called clpP-htrA), the lowest mean values for the IFN- $\gamma$ and the highest one for the MMP-9
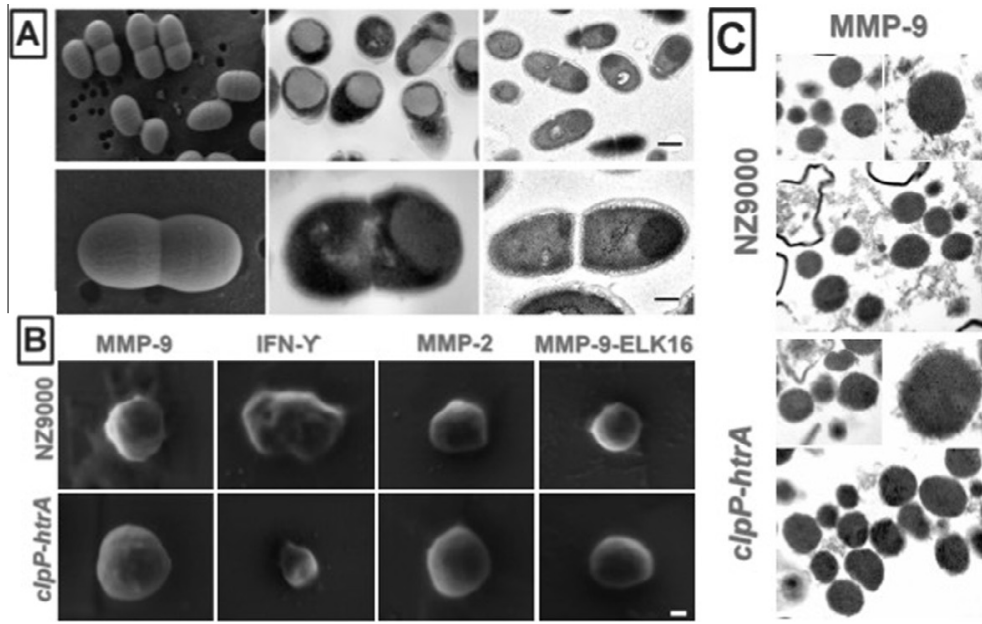

IFN-Y

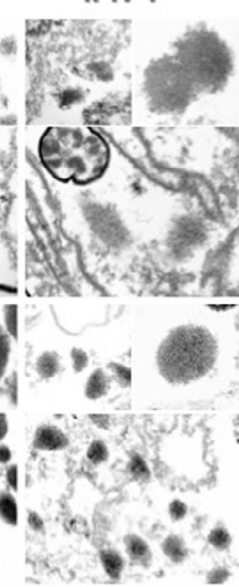

MMP-2

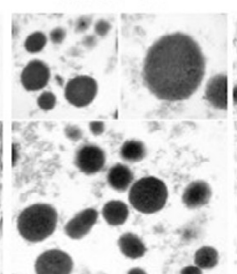

MMP-9-ELK16

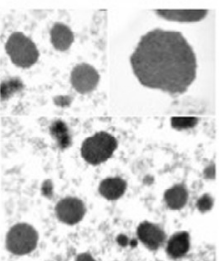

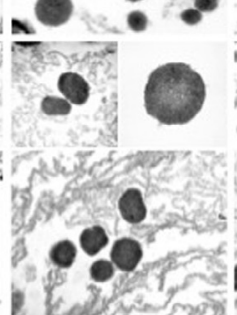
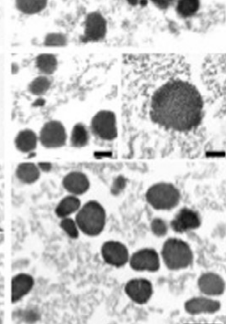

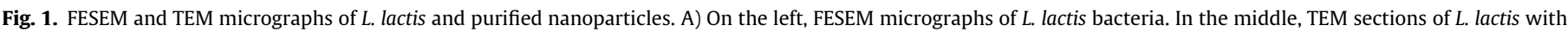

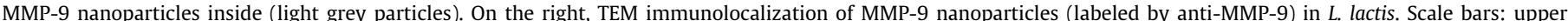

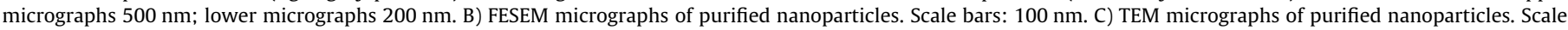
bars: left inset $200 \mathrm{~nm}$; right inset $100 \mathrm{~nm}$; lower micrographs $500 \mathrm{~nm}$. 
Table 1

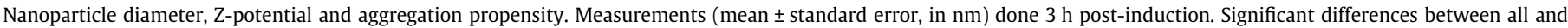
each productive strains are indicated by superscripts.

\begin{tabular}{|c|c|c|c|c|c|c|c|c|c|c|c|c|}
\hline & \multicolumn{4}{|l|}{ NZ9000 } & \multicolumn{4}{|l|}{ clpP-htrA } & \multirow[t]{2}{*}{ SEM } & \multicolumn{3}{|l|}{ p value } \\
\hline & MMP-9 & IFN- $\gamma$ & MMP-2 & MMP-9-ELK16 & MMP-9 & IFN- $\gamma$ & MMP-2 & MMP-9-ELK16 & & Protein & Strain & Protein $\times$ strain \\
\hline Diameter & $353.21^{\mathrm{c}, \mathrm{d}}$ & $422.35^{\mathrm{a}, \mathrm{b}, \mathrm{c}}$ & $387.54^{\mathrm{b}, \mathrm{c}}$ & $410.58^{\mathrm{a}, \mathrm{b}}$ & $431.58^{\mathrm{a}}$ & $317.04^{\mathrm{d}}$ & $391.84^{\mathrm{a}, \mathrm{b}, \mathrm{c}}$ & $402.84^{\mathrm{a}, \mathrm{b}, \mathrm{c}}$ & 13.91 & 0.2965 & 0.4895 & $<0.0001$ \\
\hline Z-potential & $-29.6^{\mathrm{b}, \mathrm{c}}$ & $-28.43^{\mathrm{b}, \mathrm{c}, \mathrm{d}}$ & $-33.83^{\mathrm{a}}$ & $-26.23^{\mathrm{c}, \mathrm{d}}$ & $-30.77^{\mathrm{a}, \mathrm{b}}$ & $-26.77^{\mathrm{c}, \mathrm{d}}$ & $-27.5^{\mathrm{b}, \mathrm{c}, \mathrm{d}}$ & $-25.27^{d}$ & 0.70 & $<0.0001$ & 0.012 & 0.0006 \\
\hline Aggregation (\%) & $99.24^{\mathrm{a}, \mathrm{b}}$ & $14.76^{\mathrm{a}}$ & $92.13^{\mathrm{a}, \mathrm{b}}$ & $97.33^{c}$ & $98.27^{\mathrm{b}, \mathrm{c}}$ & $3.07^{\mathrm{b}, \mathrm{c}}$ & $100^{\mathrm{a}}$ & $100^{\mathrm{a}}$ & 0.18 & 0.0121 & 0.9947 & $<0.0001$ \\
\hline
\end{tabular}

(Table 1). The statistical analysis showed that the size of the particles was determined by the combination of the specific protein and the strain. Thus, MMP-9 round particles (Fig. 1B) were bigger in clpP-htrA strain than those produced in wild type strain NZ9000 (Table 1). In marked contrast, more elongated IFN- $\gamma$ nanoparticles (Fig. 1B) showed high variable size and shape and higher mean values when produced in the NZ9000 strain (Table 1).

\subsection{Electrodensity and immunolocalization analysis of L. lactis nanoparticles}

The internal ultrastructure reported by TEM (Fig. 1C) not only strengthened the analysis performed by FESEM (Fig. 1B), but also showed that the electrodensity of protein aggregates is again protein- and strain-dependent. Interestingly, the electrodensity and compactness observed by TEM (Fig. 1C) perfectly correlated with the solubility of each protein (Table 1). The higher the solubility of a protein was, the less prone to form protein nanostructures it was. Among tested proteins, IFN- $\gamma$ showed higher solubility and its nanoparticles presented low electrodensity and a less compact ultrastructure (Fig. 1C). Additionally, these particles, in marked contrast to what occurred with particles formed by prone to aggregate proteins (such as MMPs, that formed highly compact, smooth surface and round-shaped nanostructures), exhibited rough surface and more variable size and shape (Fig. 1B). To evaluate in more detail the distribution of the protein forming such nanomaterial we performed an immunolocalization of purified nanoparticles using TEM. Ultrathin section of central parts of MMPs nanoparticles showed cortical electrodense parts of the nanostructure (heavily labeled), whereas central and less electrodense areas were less marked (or not marked) (Fig. 2). This finding, observed both in nanoparticles located inside cells (Fig. 1C) and in purified material (Fig. 2), was indicative of high differences in protein concentrations in cortical and central parts of nanoparticles.

\subsection{Study of the stability and supramolecular organization of L. lactis} nanoparticles

The structure and stability of the protein forming such nanomaterials were important parameters to be dissected. Z-potential measurements showed that all nanoparticles present negatively charged surfaces with large negative values ranging from -33 to $-26 \mathrm{mV}$ (Table 1), which is indicative of the stability of the suspension. To get further detail of supramolecular organization of nanoparticles produced in L. lactis, a time-course of proteolytic stability was performed (Fig. 3). After proteinase K treatment, the three evaluated proteins showed a population susceptible to degradation (population 1), with half-life values in the same range for all proteins (Fig. 3). Besides, a fully resistant population (population 2), ranging from $33 \%$ to $40 \%$, was preserved. Thus, nanoparticles produced in $L$. lactis presented two differentiated populations in terms of proteolytic resistance (Fig. 3).

\subsection{Determination of L. lactis nanoparticles functionality in vitro}

At this point it was critical to determine the biological activity of the nanoparticles, produced and purified for the first time from L. lactis. Fig. 4A shows that nanoparticles of proteins relevant for human and veterinary medicine produced in L. lactis were biologically functional. All MMPs tested showed the ability to degrade the substrate in a strain- and protein-dependent manner (Fig. 4A). It is worth mentioning that it was also possible to modulate the conformational quality of the protein embedded in such nanomaterials (Fig. 4A). The selection of the appropriate strain would allow increasing the specific activity of $L$. lactis nanoparticles, as it occurs with MMP-9. Besides, MMP-9 improves its specific activity, just by the presence of an aggregation tag (ELK16) fused to the protein (the observed activity corresponds to the activity of $0.08 \mathrm{ng}$ of soluble MMP-9 protein). Moreover, the statistical analysis indicated that the strain, combined with the protein used, are
MMP-9

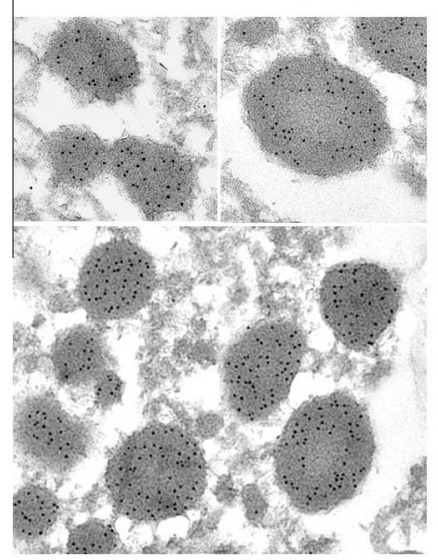

IFN-Y

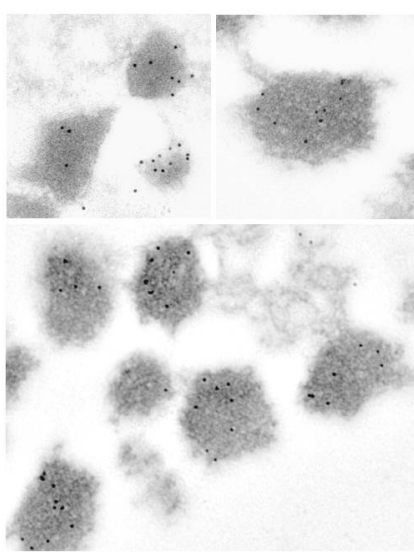

MMP-2

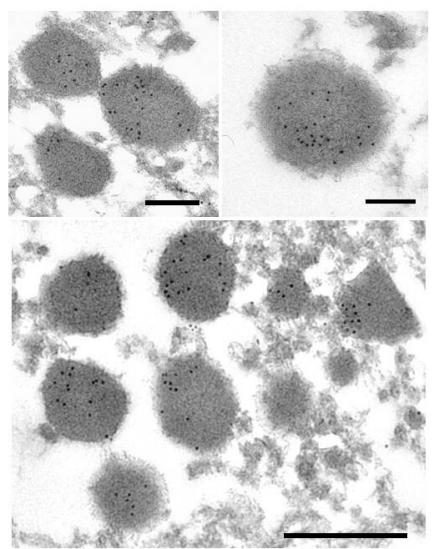

Fig. 2. TEM micrographs of purified nanoparticles labeled by specific antibodies. Scale bars: left and right inset $200 \mathrm{~nm}$; lower micrographs $500 \mathrm{~nm}$. 
MMP-9

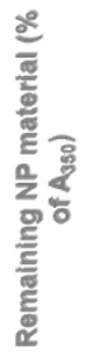

IFN-Y

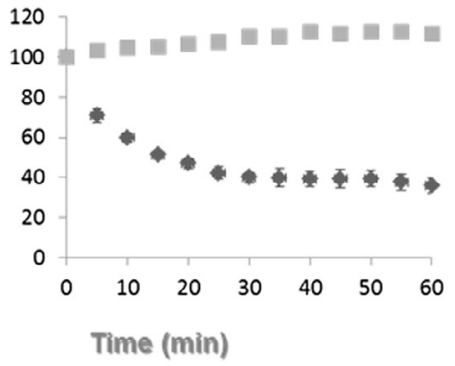

MMP-2

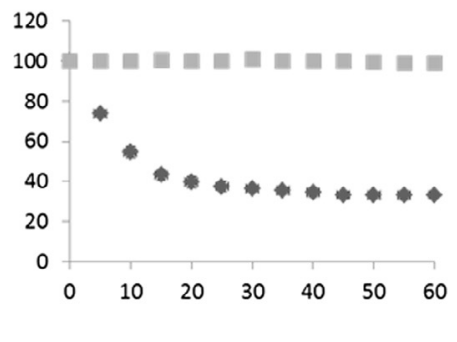

\begin{tabular}{|c|c|c|c|c|c|c|}
\hline & \multicolumn{2}{|c|}{ MMP-9 } & \multicolumn{2}{|c|}{ IFN-Y } & \multicolumn{2}{|c|}{ MMP-2 } \\
\hline & Percentage (\%) & $t_{50}(\min )$ & Percentage (\%) & $t_{50}(\min )$ & Percentage (\%) & $t_{50}(\min )$ \\
\hline Population 1 & $60.56 \pm 3.81$ & $11.47 \pm 1.98$ & $60.76 \pm 4,50$ & $6.52 \pm 0.50$ & $67.53 \pm 2.80$ & $6.16 \pm 0.53$ \\
\hline Population 2 & $40.18 \pm 3.11$ & $\infty$ & $38.16 \pm 5.37$ & $\infty$ & $33.24 \pm 2.56$ & $\infty$ \\
\hline
\end{tabular}

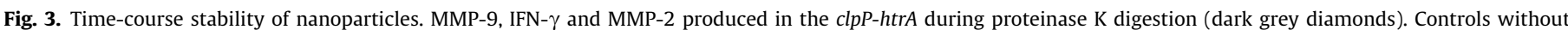

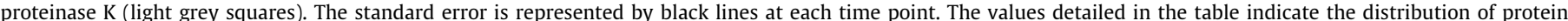
populations in the nanoparticles according to their half-life under proteinase $\mathrm{K}$ treatment.

A

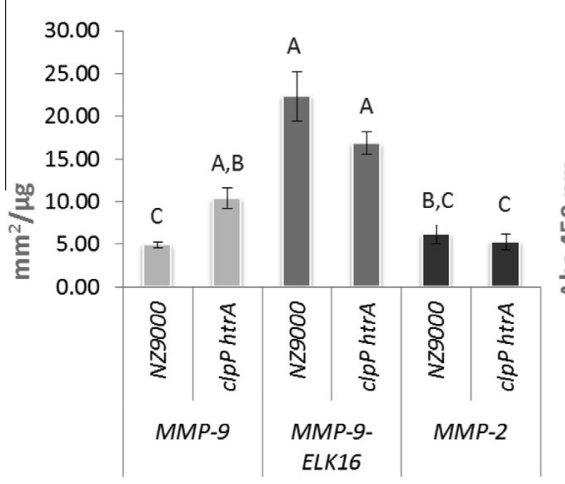

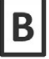

$B$

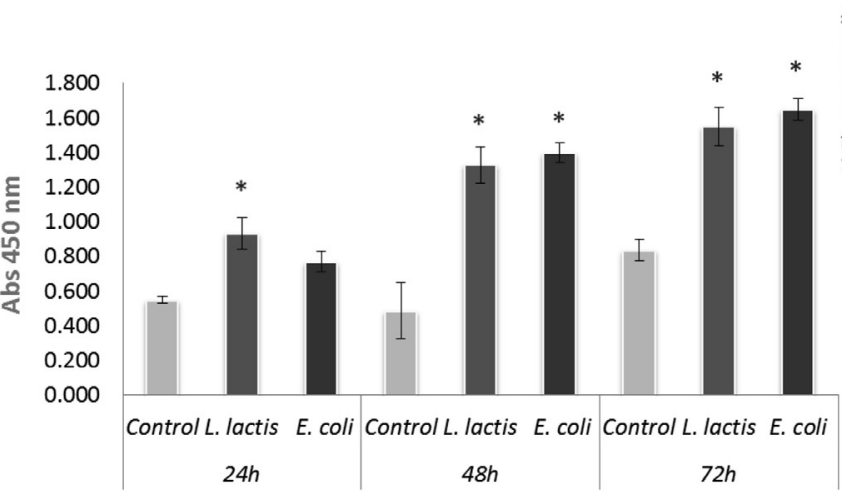

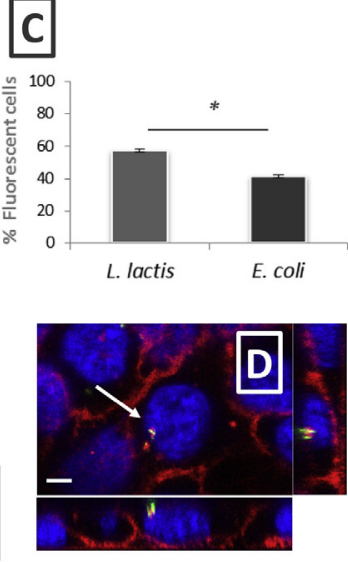

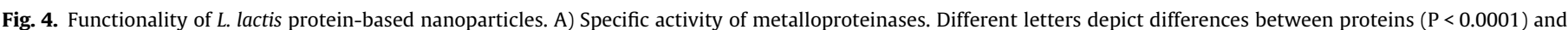

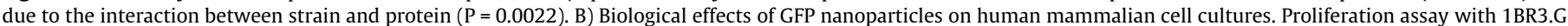

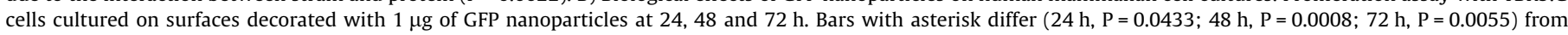

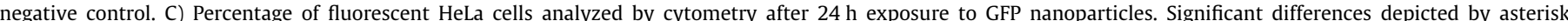

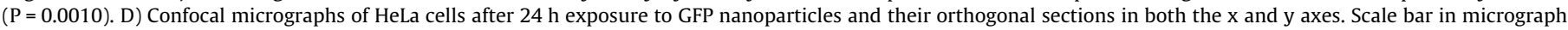
represents $5 \mu \mathrm{m}$. In all cases, results are expressed as means of non-transformed data $\pm \mathrm{SE}$, which correspond to un-transformed data.

important parameters to take into account in the production of such functional protein delivery agents in safe production systems.

Interestingly, data obtained from the FTIR analysis confirmed the coexistence of intermolecular $\beta$-sheets in nanoparticles (components at around 1695 and $1627 \mathrm{~cm}^{-1}$ ) with the presence of native-like structures (Fig. 5 and Suppl Fig. 2) [33,34]. These two populations perfectly correlated with the model mentioned above (Fig. 2), in which resistant (intermolecular $\beta$-sheets) and sensitive (native-like structures)-proteinase $\mathrm{K}$ populations coexisted in the same nanostructure. As an example, the second derivative spectra of MMP-9 and MMP-9-ELK16 were dominated by the marker bands of intermolecular $\beta$-sheets in protein aggregates, but an important component around $1658 \mathrm{~cm}^{-1}$ was also present, indicating the occurrence of native-like $\alpha$-helices and random coil structures. The comparison of MMP-9 and MMP-9-ELK16 spectra allowed concluding that MMP-9-ELK16 was characterized by a lower level of aggregation, particularly in the case of clpP-htrA sample. This was in agreement with a higher specific activity observed for these nanoparticles (Fig. 4A).

The ability to stimulate cell proliferation is another interesting property of IBs from E. coli. Interestingly, surfaces decorated with the protein-based nanomaterial produced in L. lactis were also able to stimulate the proliferation of mammalian cells at a level similar to that achieved by the particles produced in E. coli (Fig. 4B). Moreover, $L$. lactis nanoparticles were able to internalize inside the cells even more efficiently than those produced in E. coli (Fig. 4C and D). 


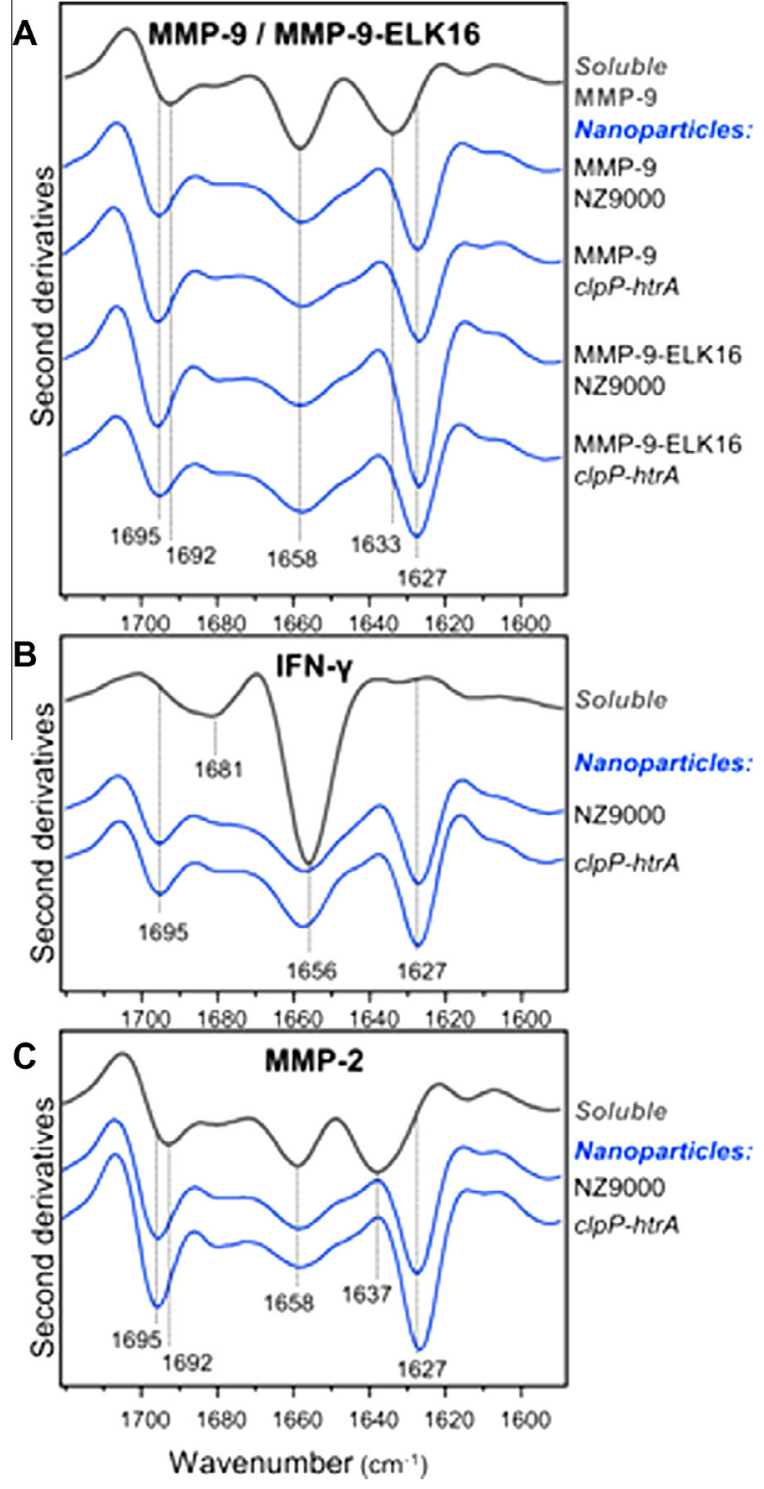

Fig. 5. FTIR analysis of purified nanoparticles. Second derivatives of absorption spectra of A) MMP-9 and MMP-9-ELK16; the component around $1658 \mathrm{~cm}^{-1}$ can be assigned to $\alpha$-helices and random coils and the two components at around $1633 \mathrm{~cm}^{-1}$ and $1692 \mathrm{~cm}^{-1}$ to the native intramolecular $\beta$-sheet structures of the protein. B) IFN- $\gamma$; the components around 1656 and $1681 \mathrm{~cm}^{-1}$ can be assigned to the native $\alpha$-helices and to turn structures of the protein, respectively. C) MMP-2; the component around $1637 \mathrm{~cm}^{-1}$, along with the peak at $\sim 1692 \mathrm{~cm}^{-1}$, can be assigned to native, intramolecular $\beta$-sheets. The component around $1658 \mathrm{~cm}^{-1}$ is due to the native $\alpha$-helices and to the random-coil structures of the protein. In A), B) and $C$ ) the two components at around 1627 and $1695 \mathrm{~cm}^{-1}$ are the typical marker bands of intermolecular $\beta$-sheets in protein aggregates.

\subsection{Study of the hydrophilic/hydrophobic nature of L. lactis nanoparticles}

Because it has been already described that the hydrophilicity of a surface influences cell adhesion properties [39], we determined the nanoparticles wettability. Thus, the wettability of mixed selfassembled monolayers (SAMs) on gold substrates before and after being functionalized with $L$. lactis nanoparticles was determined via contact angle (CA) measurements (Fig. 6). As expected, prior to nanoparticle deposition the CA decreased as the hydrophilicity of the SAM increased. An increase of $10 \%$ of the molar fraction of OH-terminated thiols implied a decrease of $6^{\circ}$ of the contact angle of the SAM-covered substrates. However, after MMP-9 nanoparticle deposition, the reduction of the contact angle in response to a $10 \%$-increase of the hydrophilic thiols concentration relative to the hydrophobic one was smaller $\left(4.0^{\circ}\right.$ in NZ9000 and $2.1^{\circ}$ in clpP-htrA). Regarding MMP-2, after deposition of both strains, the contact angle remained rather constant around $60^{\circ}$, which was an indication of its higher hydrophilic character. The MMP-9-ELK16 presented different wettability properties depending on the genetic variant it was obtained from. Thus, MMP-9-ELK16 derived from the wild type strain rendered also a constant contact angle around $60^{\circ}$ but the one obtained from clpP-htrA strain showed a reduction of $3^{\circ}$ of the contact angle in response to a $10 \%$-increase of the hydrophilic thiols concentration. After IFN- $\gamma$ deposition produced in both strains, the contact angle remained rather constant at around $65-70^{\circ}$. From the change of CA after nanoparticle deposition, we concluded that the deposition of nanoparticles produced in $L$. lactis buffered the change of wettability of the substrates. On the other hand, IFN- $\gamma$ and MMP-2 nanoparticles kept wettability relatively constant around a certain value.

Coverages of nanoparticle surfaces are shown in Table 2. From these data, it was possible to affirm that the affinity of protein nanostructures toward hydrophilic and/or hydrophobic surfaces also depended on the genetic background in which they have been produced. Thus, the interactions between these protein-based biomaterials and substrates, and the density of deposited nanoparticles can be tuned to a certain extent choosing a specific $L$. lactis strain. With MMP-2 and MMP-9-ELK16 there was a higher coverage and higher affinity of the nanoparticles towards the substrate for the NZ9000 than for the genetically modified clpP-htrA. Regarding the MMP-9 and the IFN- $\gamma$, the potential difference between NZ9000 and the mutant strain was not clear. The surface coverage significantly varied also in response to changes of substrate wettability. For some proteins, high coverages were obtained for substrates of different wettability, which could be attributed to the presence of amphiphilic properties of the obtained nanoparticles.

\section{Discussion}

E. coli IBs have been shown to be a mechanically stable nanomaterial with interesting properties as a drug delivery system, but also as a promising biomaterial for tissue engineering. However, the use of $E$. coli as recombinant cell factory for their production has an important shortcoming. Because of their endotoxic nature due to the presence of LPS, even at low concentration, IBs can trigger a non-desired immunogenic response upon administration. Therefore, any E. coli-derived product have to be necessarily further purified through a time-consuming, costly, and, in many cases, ineffective depyrogenation process [14]. For this reason, and with the goal of producing protein-based biomaterials in an endotoxin-free environment, we explored L. lactis as cell factory. Although $L$. lactis has already been proven to be an excellent choice for the production of other LPS-free biomaterials such as polyhydroxybutyrate (PHB), the main mechanical and chemical properties of protein-based nanostructures produced in this Gram-positive microorganism have never been studied. Thus, the present study shows for the first time an accurate analysis of a novel protein-based nanomaterial produced in a safe cell factory, which sets the basis to further explore the applicability of this platform to produce biomaterials for the pharmaceutical industry.

As starting point, we successfully produced and isolated such nanomaterial from $L$. lactis. The obtained nanoparticles were carefully assessed by high resolution microscopy techniques, noticing that proteins acting as building blocks of these nanoparticles are heterogeneously distributed within the nanomaterial (Fig. 2). In particular, immunolocalization analysis revealed high differences 


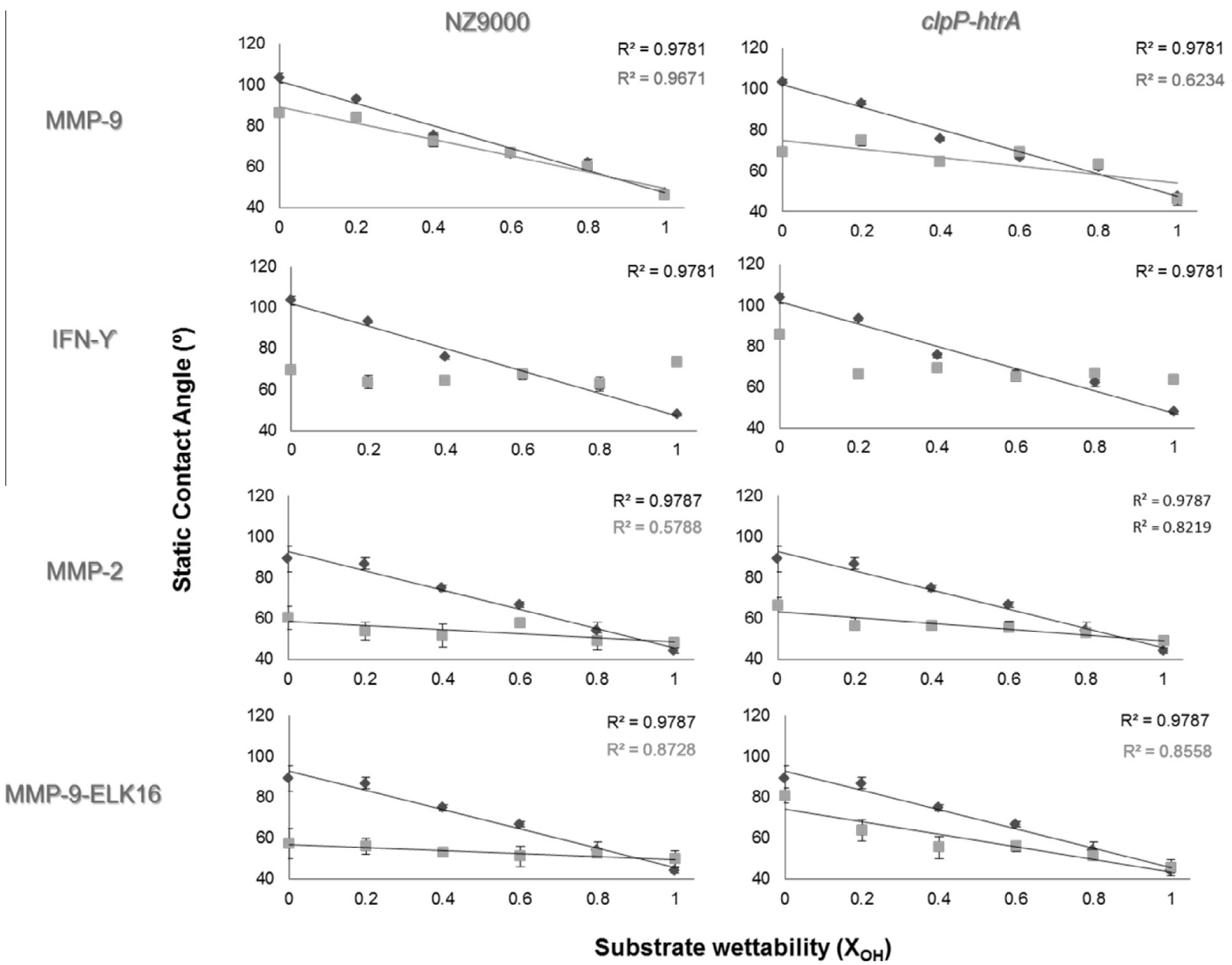

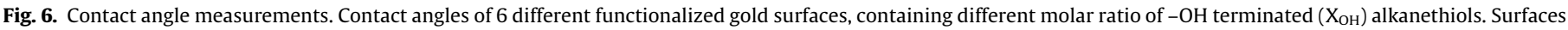
before nanoparticle deposition (dark grey diamond) and after nanoparticle deposition (light grey square).

Table 2

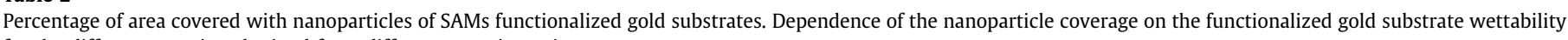
for the different proteins obtained from different genetic strains.

\begin{tabular}{|c|c|c|c|c|c|c|c|c|}
\hline \multirow[t]{2}{*}{ Substrate $\left(\mathrm{X}_{\mathrm{OH}}\right)$} & \multicolumn{2}{|l|}{ MMP-9 } & \multicolumn{2}{|l|}{ IFN- $\gamma$} & \multicolumn{2}{|l|}{ MMP-2 } & \multicolumn{2}{|c|}{ MMP9-ELK16 } \\
\hline & NZ9000 & clpP-htrA & NZ9000 & clpP-htrA & NZ9000 & clpP-htrA & NZ9000 & clpP-htrA \\
\hline 0 & 0.14 & 1.54 & 0.41 & 0.47 & 6.31 & 2.74 & 11.44 & 5.32 \\
\hline 0.2 & 0.22 & 0.89 & 0.40 & 1.31 & 5.61 & 1.74 & 19.36 & 3.46 \\
\hline 0.4 & 0.23 & 1.66 & 0.68 & 0.4 & 5.26 & 2.75 & 14.73 & 5.70 \\
\hline 0.6 & 0.58 & 0.61 & 1.91 & 0.23 & 10.38 & 1.03 & 15.02 & 11.24 \\
\hline 0.8 & 0.20 & 1.56 & 2.17 & 0.29 & 12.05 & 0.81 & 4.26 & 4.27 \\
\hline 1 & 0.39 & 0.37 & 1.39 & 0.43 & 15.14 & 3.30 & 13.70 & 1.14 \\
\hline
\end{tabular}

in protein concentrations in cortical and central parts of nanoparticles, with cortical regions being much richer in protein than particle core ones. This was probably related to the activity of cell mechanisms during nanostructure formation and growth, previously observed in IB formation [30]. In addition, the ultrastructure observed by FESEM and TEM (Fig. 1 and Table 1) also resembled that of IBs formed in E. coli $[3,30,40]$. Interestingly, our data proved that nanoscale features such as size, compactness and shape can be easily tailored by selecting the appropriate combination of protein and strain (Table 1, Fig. 1B and C). The interaction between strain and protein had also a clear effect on the biological activity of our nanoparticles (Fig. 4A). This finding opens a range of possibilities in the customization of this functional and safe biomaterial. This is particularly interesting considering that these protein-based nanomaterials can be also genetically engineered, being possible not only to define size, shape and electrodensity, but also the organization and the biological activity of the produced protein-based nanoparticles in this safe microorganism. Considering the enzymatic activity of MMP nanoparticles obtained herein (Fig. 4A) and their ability to stimulate cell proliferation (Fig. 4B), this biomaterial has a great potential for both drug delivery (Fig. 4A) and tissue engineering purposes (Fig. 4B).

It has also been described that $E$. coli IBs show a bimodal supramolecular organization of the embedded protein. In this case, E. coli IBs contain a fraction of protein ranging from 9 to $33 \%$ with an amyloid-like organization, which is fully resistant to proteinase $\mathrm{K}$ and acts as a nanoparticle scaffold, and two other protein populations, one of them being immediately degraded and another one 
sensitive to proteinase $\mathrm{K}$ digestion being associated with the biological activity shown by IBs [32]. The food-grade nanomaterial characterized in the present study exhibited a degradable population, with a half-life comparable to the populations described in E. coli [32], and a resistant population (Fig. 3). The coexistence of these two distinguished populations was further confirmed by FTIR analysis (Fig. 5). Proteins adopting an intermolecular $\beta$-sheet conformation would correspond to the proteinase-K resistant population, whereas proteinase-K sensitive population exhibited a nativelike structure which contributed to its remarkable biological activity.

The determination of the chemical properties of these nanoparticles also supports that such nanoclusters have many characteristics in common with those obtained when using E. coli as cell factory. Depending on the genetic background chosen to produce the nanoparticles, the wettability properties of the nanostructures and thus, the wettability of surfaces modified with them, can be modulated [5]. Besides, the presence of a simple aggregation tag, such as ELK16 in MMP-9, clearly modifies the behavior of the nanostructure. However, $\mathrm{Z}$ potential values of $L$. lactis-derived nanoparticles determined in this study are higher than those observed in IBs produced in LPS-enriched environment [5], indicating that, although endotoxin-free nanostructures share many characteristics with those derived from $E$. coli, they are more stable in suspension.

Considering E. coli limitations, this study opens a range of possibilities in terms of applications. The implementation of LAB as a routine cell factory for the production of functional nanomaterials would allow the development of safe production processes, avoiding at the same time complex downstream purification steps to eliminate toxic components.

\section{Conclusions}

Data presented in this study reveal for the first time, that it is possible to produce, tune and isolate endotoxin-free IB-like nanoparticles from LAB through a cost-effective and fully scalable process. The results provide evidence that under overexpression conditions, L. lactis is able to produce protein nanoparticles bearing similar properties than those produced in E. coli. Interestingly, these functional nanostructures isolated from L. lactis show even higher stabilities and activity than those obtained from E. coli. This finding allows making a qualitative step, since it opens a field of opportunities for the production of recombinant proteins in a cost-effective format using GRAS systems as cell factories. Overall, these data indicate that $\mathrm{LAB}$ are ideal alternatives for the synthesis of tuned protein-based endotoxin-free nanoparticles for a wide range of applications in both human and veterinary medicine.

\section{Acknowledgements}

This work was supported by grants from INIA, MINECO, Spain to AA and EGF (RTA2012-00028-C02-02), from DGI to JV (BeWell CTQ2013-40480-R), from MINECO to EGF and IR (MAT301350036-EXP) and to ICMAB (Severo Ochoa Programme for Centres of Excellence in R\&D - SEV - 2015-0496), from Agència de Gestió d'Ajuts Universitaris i de Recerca to AV and JV (2014SGR-132 and 2014-SGR-17, respectively) and from EU to JV, AV and IR (H2020-INFRAIA-2014-2015; NFFA-654360). Besides, the authors acknowledge the financial support granted to AV and JV from the Centro de Investigación Biomédica en Red (CIBER) de Bioingeniería, Biomateriales y Nanomedicina financed by the Instituto de Salud Carlos III with assistance from the European Regional Development. OCG and WIT received a PhD fellowship from MECD (FPU) and CSIC (JAE-pre), respectively, and EGF a post-doctoral fellowship from INIA (DOC-INIA). AV has been distinguished with an ICREA ACADEMIA Award. The authors also acknowledge Micalis Institute, INRA, France that kindly provide us the strain clpP $^{-}$htrA $A^{-}$-NZ9000 (patent ${ }^{\circ}$ EP1141337B1/US6994997B1). We are also indebted to "Servei de Microscopia" (UAB) and ICTS "NANBIOSIS", more specifically to the Protein Production Platform of CIBER in Bioengineering, Biomaterials \& Nanomedicine (CIBERBBN)/IBB, at the UAB SepBioES scientific-technical service (http:// www.nanbiosis.es/unit/u1-protein-production-platform-ppp/). No other potential conflicts of interest were identified.

\section{Appendix A. Supplementary data}

Supplementary data associated with this article can be found, in the online version, at http://dx.doi.org/10.1016/j.actbio.2016.07. 038 .

\section{References}

[1] N. Ferrer-Miralles, E. Rodriguez-Carmona, J.L. Corchero, E. Garcia-Fruitos, E. Vazquez, A. Villaverde, Engineering protein self-assembling in protein-based nanomedicines for drug delivery and gene therapy, Crit. Rev. Biotechnol. 35 (2015) 209-221.

[2] E. Garcia-Fruitos, E. Vazquez, C. Diez-Gil, J.L. Corchero, J. Seras-Franzoso, I. Ratera, J. Veciana, A. Villaverde, Bacterial inclusion bodies: making gold from waste, Trends Biotechnol. 30 (2012) 65-70.

[3] X. Wang, B. Zhou, W. Hu, Q. Zhao, Z. Lin, Formation of active inclusion bodies induced by hydrophobic self-assembling peptide GFIL8, Microb. Cell Fact. 14 (2015) 88.

[4] A. Singh, V. Upadhyay, A.K. Panda, Solubilization and refolding of inclusion body proteins, Methods Mol. Biol. 1258 (2015) 283-291.

[5] C. Diez-Gil, S. Krabbenborg, E. Garcia-Fruitos, E. Vazquez, E. RodriguezCarmona, I. Ratera, N. Ventosa, J. Seras-Franzoso, O. Cano-Garrido, N. FerrerMiralles, A. Villaverde, J. Veciana, The nanoscale properties of bacterial inclusion bodies and their effect on mammalian cell proliferation, Biomaterials 31 (2010) 5805-5812.

[6] Y. Loo, M. Goktas, A.B. Tekinay, M.O. Guler, C.A. Hauser, A. Mitraki, Selfassembled proteins and peptides as scaffolds for tissue regeneration, Adv Healthcare Mater. 4 (2015) 2557-2586.

[7] A. Villaverde, E. Garcia-Fruitos, U. Rinas, J. Seras-Franzoso, A. Kosoy, J.L. Corchero, E. Vazquez, Packaging protein drugs as bacterial inclusion bodies for therapeutic applications, Microb. Cell Fact. 11 (2012) 76.

[8] S.J. Wakelin, I. Sabroe, C.D. Gregory, I.R. Poxton, J.L. Forsythe, O.J. Garden, S.E Howie, "Dirty little secrets"-endotoxin contamination of recombinant proteins, Immunol. Lett. 106 (2006) 1-7.

[9] F. Rueda, O. Cano-Garrido, U. Mamat, K. Wilke, J. Seras-Franzoso, E. GarciaFruitos, A. Villaverde, Production of functional inclusion bodies in endotoxinfree Escherichia coli, Appl. Microbiol. Biotechnol. 98 (2014) 9229-9238.

[10] D. Petsch, F.B. Anspach, Endotoxin removal from protein solutions, J. Biotechnol. 76 (2000) 97-119.

[11] L.N. Beenken-Rothkopf, L.S. Karfeld-Sulzer, X. Zhang, H. Kissler, S.A. Michie, D. B. Kaufman, M.J. Fontaine, A.E. Barron, Protein polymer hydrogels: effects of endotoxin on biocompatibility, J. Biomater. Appl. 28 (2013) 395-406.

[12] S. Taguchi, T. Ooi, K. Mizuno, H. Matsusaki, Advances and needs for endotoxinfree production strains, Appl. Microbiol. Biotechnol. 99 (2015) 9349-9360.

[13] A. Villaverde, J.L. Corchero, J. Seras-Franzoso, E. Garcia-Fruitos, Functiona protein aggregates: just the tip of the iceberg, Nanomedicine (Lond) 10 (2015) 2881-2891.

[14] N.A. Parlane, K. Grage, J.W. Lee, B.M. Buddle, M. Denis, B.H. Rehm, Production of a particulate hepatitis $C$ vaccine candidate by an engineered Lactococcus lactis strain, Appl. Environ. Microbiol. 77 (2011) 8516-8522.

[15] O. Cano-Garrido, J. Seras-Franzoso, E. Garcia-Fruitos, Lactic acid bacteria: reviewing the potential of a promising delivery live vector for biomedical purposes, Microb. Cell Fact. 14 (2015) 137.

[16] E. Garcia-Fruitos, Lactic acid bacteria: a promising alternative for recombinant protein production, Microb. Cell Fact. 11 (2012) 157.

[17] W.N. Konings, J. Kok, O.P. Kuipers, B. Poolman, Lactic acid bacteria: the bugs of the new millennium, Curr. Opin. Microbiol. 3 (2000) 276-282.

[18] W.W. Lu, J. Kong, W.T. Kong, Construction and application of a food-grade expression system for Lactococcus lactis, Mol. Biotechnol. 54 (2013) 170-176.

[19] O. Cano-Garrido, F.L. Rueda, L. Sanchez-Garcia, L. Ruiz-Avila, R. Bosser, A. Villaverde, E. Garcia-Fruitós, Expanding the recombinant protein quality in Lactococcus lactis, Microb. Cell Fact. 13 (2014) 167.

[20] I. Mierau, M. Kleerebezem, 10 years of the nisin-controlled gene expression system (NICE) in Lactococcus lactis, Appl. Microbiol. Biotechnol. 68 (2005) 705717.

[21] M.S. King, C. Boes, E.R. Kunji, Membrane protein expression in Lactococcus lactis, Methods Enzymol. 556 (2015) 77-97.

[22] N.G. Cortes-Perez, I. Poquet, M. Oliveira, J.J. Gratadoux, S.M. Madsen, A. Miyoshi, G. Corthier, V. Azevedo, P. Langella, L.G. Bermúdez-Humaran, 
Construction and characterization of a Lactococcus lactis strain deficient in intracellular ClpP and extracellular HtrA proteases, Microbiology 152 (2006) 2611-2618

[23] I. Poquet, V. Saint, E. Seznec, N. Simoes, A. Bolotin, A. Gruss, HtrA is the unique surface housekeeping protease in Lactococcus lactis and is required for natural protein processing, Mol. Microbiol. 35 (2000) 1042-1051.

[24] J.G. Thomas, F. Baneyx, Roles of the Escherichia coli small heat shock proteins IbpA and IbpB in thermal stress management: comparison with ClpA, ClpB, and HtpG in vivo, J. Bacteriol. 180 (1998) 5165-5172.

[25] H. Holo, I.F. Nes, High-frequency transformation, by electroporation, of Lactococcus lactis subsp. cremoris grown with glycine in osmotically stabilized media, Appl. Environ. Microbiol. 55 (1989) 3119-3123.

[26] E. Garcia-Fruitos, N. Gonzalez-Montalban, M. Morell, A. Vera, R.M. Ferraz, A. Aris, S. Ventura, A. Villaverde, Aggregation as bacterial inclusion bodies does not imply inactivation of enzymes and fluorescent proteins, Microb. Cell Fact. 4 (2005) 27.

[27] J. Seras-Franzoso, S. Peternel, O. Cano-Garrido, A. Villaverde, E. Garcia-Fruitos, Bacterial inclusion body purification, Methods Mol. Biol. 1258 (2015) 293305.

[28] T. Mussá, C. RodríguezCariño, A. Sánchez-Chardi, M. Baratelli, M. CostaHurtado, L. Fraile, J. Domínguez, V. Aragon, M. Montoya, Differential interactions of virulent and non-virulent $H$. parasuis strains with naïve or swine-influenza virus pre-infected dendritic cells, Vet. Res. 43 (2012) 80.

[29] C. Rodriguez-Carino, C. Duffy, A. Sanchez-Chardi, F. McNeilly, G.M. Allan, J. Segales, Porcine circovirus type 2 morphogenesis in a clone derived from the 135 lymphoblastoid cell line, J. Comp. Pathol. 144 (2011) 91-102.

[30] J. Seras-Franzoso, A. Sanchez-Chardi, E. Garcia-Fruitos, E. Vazquez, A. Villaverde, Cellular uptake and intracellular fate of protein releasing bacterial amyloids in mammalian cells, Soft Matter 12 (2016) 3451-3460.

[31] C. Rodriguez-Carino, A. Sanchez-Chardi, J. Segales, Subcellular immunolocalization of porcine circovirus type 2 (PCV2) in lymph nodes from pigs with post-weaning multisystemic wasting syndrome (PMWS), J. Comp. Pathol. 142 (2010) 291-299.
[32] O. Cano-Garrido, E. Rodriguez-Carmona, C. Diez-Gil, E. Vazquez, E. Elizondo, R. Cubarsi, J. Seras-Franzoso, J.L. Corchero, U. Rinas, I. Ratera, N. Ventosa, J. Veciana, A. Villaverde, E. Garcia-Fruitós, Supramolecular organization of protein-releasing functional amyloids solved in bacterial inclusion bodies, Acta Biomater. 9 (2013) 6134-6142.

[33] D. Ami, A. Natalello, G. Taylor, G. Tonon, Doglia.S. Maria, Structural analysis of protein inclusion bodies by Fourier transform infrared microspectroscopy, Biochim. Biophys. Acta 1764 (2006) 793-799.

[34] A. Natalello, S.M. Doglia, Insoluble protein assemblies characterized by Fourier transform infrared spectroscopy, Methods Mol. Biol. 1258 (2015) 347-369.

[35] P. Bassan, A. Sachdeva, A. Kohler, C. Hughes, A. Henderson, J. Boyle, J.H. Shanks, M. Brown, N.W. Clarke, P. Gardner, FTIR microscopy of biological cells and tissue: data analysis using resonant Mie scattering (RMieS) EMSC algorithm, Analyst 137 (2012) 1370-1377.

[36] J. Seras-Franzoso, C. Diez-Gil, E. Vazquez, E. Garcia-Fruitos, R. Cubarsi, I. Ratera, J. Veciana, A. Villaverde, Bioadhesiveness and efficient mechanotransduction stimuli synergistically provided by bacterial inclusion bodies as scaffolds for tissue engineering, Nanomedicine 7 (2012) 79-93.

[37] E. Garcia-Fruitos, E. Rodriguez-Carmona, C. Diez-Gil, R.M. Ferraz, E. Vazquez, J. L. Corchero, M. Cano-Sarabia, I. Ratera, N. Ventosa, J. Veciana, A. Villaverde, Surface cell growth engineering assisted by a novel bacterial nanomaterial, Adv. Mater. 21 (2009) 4249.

[38] M. Pesarrodona, N. Ferrer-Miralles, U. Unzueta, P. Gener, W. Tatkiewicz, I. Abasolo, I. Ratera, J. Veciana, S. Schwartz Jr., A. Villaverde, E. Vazquez, Intracellular targeting of CD44+ cells with self-assembling, protein only nanoparticles, Int. J. Pharm. 473 (2014) 286-295.

[39] N. Faucheux, R. Schweiss, K. Lutzow, C. Werner, T. Groth, Self-assembled monolayers with different terminating groups as model substrates for cell adhesion studies, Biomaterials 25 (2004) 2721-2730.

[40] E. Garcia-Fruitos, J. Seras-Franzoso, E. Vazquez, A. Villaverde, Tunable geometry of bacterial inclusion bodies as substrate materials for tissue engineering, Nanotechnology 21 (2010). 